\title{
REFLECTIONS
}

\section{Thoughts on Communication}

Paul R. Gordon, MD, MPH

Department of Family \& Community Medicine, College of Medicine, University of Arizona, Tucson, Ariz
Conflicts of interest: none reported

\section{CORRESPONDING AUTHOR}

Paul R. Gordon, MD, MPH

University of Arizona

AHSC PO Box 24-5113

Tucson, AZ 85724-5113

pgordon@u.arizona.edu

\begin{abstract}
Living without the ability to communicate is humbling. Time spent on a sabbatical in Florence, Italy, taught me that my outgoing manner, my interactional skills, and my ability to establish rapport, all personality traits and skills that I thought would overcome my inadequacies as a communicator in Italian are not immutable. I gained some understanding of what our nonnative English-speaking patients might feel. I learned the following lessons: (1) be cautious-what appears to be a lack of interest may be a lack of understanding; (2) our perceptions of aptitude may be mistaken if based on patients' facial expressions and body language; (3) we should not adjust our words and speed of speech just because we think a patient cannot understand what we are saying; and (4) language is an amazingly powerful tool-the inability to communicate transforms us.
\end{abstract}

Ann Fam Med 2006;4:263-264. DOI: 10.1370/afm.551.

I

just returned from Italy. My silence ends. I am able to communicate again. I spent the last 3 months on sabbatical at a medical school in Florence, Italy. Although I did not speak Italian, I was fluent in Spanish and hoped that would be enough; even my faculty sponsor in Florence was confident that because his colleagues were all able to speak English, I would have no major problems.

I did. I'm an educated professional, reasonably outgoing, with good interpersonal skills and language facility. I thought I would easily adapt. Survival would be no problem. It was. It was a problem with those I met at the supermarket, with Italians with whom I rode to work, with neighbors doing laundry at the laundromat. It was even a problem with the man who repaired my shoes. These Italians spoke no English, and at the end of the day I found myself staying at home alone to avoid any kind of personal contact.

On the bus ride to the hospital every morning, I found myself avoiding eye contact - the same eye contact I suggest my medical students use to improve their communication with patients. I was afraid to look at anyone fearing that I wouldn't be able to answer simple questions, such as, "Which stop should I get off at to go to the St. Ambrosia market?" I feared, not just the inability to respond, but the embarrassment of appearing like a typical American tourist, arrogant and snobby, because he is unable to communicate in a foreign language.

In my nonprofessional life I'm a runner, and the runners I know are anything but snobs. We share friendly smiles, head nods, and slight waves of the hand, all universal signs of friendliness and camaraderie-a universal language. But one morning in Italy another runner about my age came along beside me. He made a comment—probably about the beautiful morning - and I failed to respond. In shame, I dropped my chin, speeding up to escape from him instead of running next to him. Having momentarily forgotten the universal running language I used at home, I found myself running with my head down, unable to share in the joy of a morning run with a potential running companion.

Living in this unanticipated silence gave me a newfound empathy for the nonnative English speaking patients in my practice. Do they have 
similar fears about their inability to communicate in a foreign environment? Do I draw conclusions about their character from their capacity or incapacity to communicate? Indeed, do these conclusions enter into my personal patient record of them as I provide them clinical care? What about our English-speaking patients who seek treatment in the foreign environment of the medical encounter, one in which words are not easily understood and cannot readily be found in standard dictionaries? Although our respiratory technologist patient may know about $\mathrm{ABG}$ s and hypoxemia, does he also know what we mean when we suggest his abdominal pain may be due to a mesenteric infarct?

As I reflect on my experience in Italy, knowing that this sabbatical has been both a rest and a reawakening, I find I learned the following lessons: (1) Experienced clinicians use nonverbal clues to better understand their patients. We need to be cautious - what appears to be a lack of interest may be a lack of understanding. (2) We often modify our treatment and approach in part based on perception rather than reality. Clinicians assume that patients who look puzzled or lost are unable to grasp the concepts, or that those who look unenthusiastic don't like what we're telling them. These same facial expressions and nonverbal behaviors may occur in patients who have limited English language skills; therefore, our perceptions of aptitude may be mistaken if solely based on patients' facial expressions and body language. (3) We should not adjust our words and speed of speech just because we think a patient can't understand what we are saying. For example, we might slow down our speech with wheelchair-bound patients who have suffered a stroke and now have expressive aphasia, when in fact their intelligence may be normal or above normal and their comprehension has not been impaired (4) Most importantly, I learned that language is an amazingly powerful tool. The inability to communicate transforms us. Our lack of understanding and empathy may worsen our patients' circumstances.

Now, when I teach my first-year medical students how to conduct a medical interview, I continue to remind them of the importance of nonverbal signs. I tell them that simply because a patient does not speak doesn't mean he doesn't want to or cannot. I tell them this based on lessons I learned on the bus rides and morning runs during my sabbatical in Italy.

To read or post commentaries in response to this article, see it online at http://www.annfammed.org/cgi/current/full/4/3/263.

Key words: Communication; physician-patient relations; education

Submitted July 25, 2005; submitted revised December 16, 2005; accepted December 26, 2005.

\section{CHANGE-OF-ADDRESS FORM FANMILY MEDICINE}

Please complete this form and mail to the following address or fax to Annals Circulation at 913-906-6080:

Annals of Family Medicine, Circulation Department, 11400 Tomahawk Creek Pkwy, Leawood, KS 66211-2672

Check if member of sponsoring organization: $\square$ AAFP $\square$ ABFM $\square$ STFM $\square$ ADFM $\square$ AFMRD $\square$ NAPCRG

ID number from label on your journal cover

OLD Information (Please print.)

Name

Company (if applicable)

Address (Street plus Apt or Ste)

\begin{tabular}{lc}
\hline City & \\
\hline Country & Postal Code (9-digit ZIP for US) \\
\hline Telephone & Fax \\
\hline E-Mail &
\end{tabular}

NEW Information (Please print.)

\begin{tabular}{ll}
\hline Name \\
\hline Company (if applicable) \\
\hline Address (Street plus Apt or Ste) \\
\hline City \\
\hline Country \\
\hline Telephone & Postal Code (9-digit ZIP for US) \\
\hline E-Mail & \\
\hline
\end{tabular}

